\title{
Back-propagation of physiological action potential output in dendrites of slender-tufted L5A pyramidal neurons
}

\author{
Benjamin F. Grewe ${ }^{1,2}$, Audrey Bonnan ${ }^{3}$ and Andreas Frick ${ }^{1,3 *}$ \\ Department of Cell Physiology, Max Planck Institute for Medical Research, Heidelberg, Germany \\ 2 Department of Neurophysiology, Brain Research Institute, University of Zürich, Zurich, Switzerland \\ 3 Institut National de la Santé et de la Recherche Médicale Unité 862, NeuroCentre Magendie, Circuit and dendritic mechanisms underlying cortical plasticity, Bordeaux, \\ France
}

\section{Edited by:}

Daniel Johnston,

University of Texas, USA

\section{Reviewed by:}

Nelson Spruston,

Northwestern University, USA

Jeff Magee,

Howard Hugues Medical Institute, USA

${ }^{*}$ Correspondence:

Andreas Frick

Institut National de la Santé et de la

Recherche Médicale Unité 862,

NeuroCentre Magendie, Circuit and

dendritic mechanisms underlying

cortical plasticity, Université Bordeaux

2, ENI-NET 146, rue Léo Saignat 33077

Bordeaux, France.

e-mail: andreas.frick@inserm.fr
Pyramidal neurons of layer $5 \mathrm{~A}$ are a major neocortical output type and clearly distinguished from layer 5B pyramidal neurons with respect to morphology, in vivo firing patterns, and connectivity; yet knowledge of their dendritic properties is scant. We used a combination of whole-cell recordings and $\mathrm{Ca}^{2+}$ imaging techniques in vitro to explore the specific dendritic signaling role of physiological action potential patterns recorded in vivo in layer $5 \mathrm{~A}$ pyramidal neurons of the whisker-related 'barrel cortex'. Our data provide evidence that the temporal structure of physiological action potential patterns is crucial for an effective invasion of the main apical dendrites up to the major branch point. Both the critical frequency enabling action potential trains to invade efficiently and the dendritic calcium profile changed during postnatal development. In contrast to the main apical dendrite, the more passive properties of the short basal and apical tuft dendrites prevented an efficient back-propagation. Various $\mathrm{Ca}^{2+}$ channel types contributed to the enhanced calcium signals during high-frequency firing activity, whereas A-type $\mathrm{K}^{+}$and $\mathrm{BK}_{\mathrm{Ca}}$ channels strongly suppressed it. Our data support models in which the interaction of synaptic input with action potential output is a function of the timing, rate and pattern of action potentials, and dendritic location.

\section{INTRODUCTION}

In cortical pyramidal neurons, action potentials (APs) are initiated in the axon and back-propagate into their dendritic arbors both in vitro and in vivo (Stuart and Sakmann, 1994; Larkum and Zhu, 2002; Waters et al., 2003; Bereshpolova et al., 2007); APs backpropagate into the basal (Antic, 2003; Kampa and Stuart, 2006; Nevian et al., 2007), oblique (Antic, 2003; Frick et al., 2003), and apical main and tuft dendrites (Schiller et al., 1995; Williams and Stuart, 2000; Larkum and Zhu, 2002). Some of the suggested functional roles of these back-propagating APs (bAPs) are to serve as a feedback signal to the dendrites and to interact with synaptic signals to regulate dendritic plasticity and neuronal AP output (Frick and Johnston, 2005; Waters et al., 2005; Sjöström et al., 2008). Back-propagation is active in cortical pyramidal neurons, but the amplitude of the bAPs gradually decreases with distance from soma. This decline depends on numerous factors such as coincidence with incoming synaptic input (Larkum et al., 1999; Stuart and Hausser, 2001), intrinsic excitability (Bernard and Johnston, 2003; Frick et al., 2004), inhibition (Larkum, 1999), and morphology (Schaefer et al., 2003). Another important factor determining the reliability of back-propagation is the frequency of the AP output (Spruston et al., 1995; Stuart et al., 1997; Larkum, 1999; Williams and Stuart, 2000).

Layer 5A (L5A) pyramidal neurons are a major type of output neurons in neocortical circuits. These neurons differ from L5B pyramidal neurons in many ways, including the morphology of their dendritic arbors, their intra- and sub-cortical connectivity, and firing properties in response to physiological stimuli (Manns et al., 2004; Schubert et al., 2006; de Kock et al., 2007; Frick et al., 2007; Lefort et al., 2009; Petreanu et al., 2009). In the barrel cortex of rodents the firing of neocortical neurons is sparse with low mean frequencies (Brecht, 2002; Celikel et al., 2004; Crochet and Petersen, 2006; de Kock et al., 2007). L5A pyramidal neurons, for instance, respond to whisker stimulation with on average $<1 \mathrm{AP}$ per stimulus in anesthetized animals, and increase their firing rate to $\sim 5 \mathrm{~Hz}$ during whisking episodes (de Kock and Sakmann, 2009); nevertheless, their firing patterns are highly irregular and consist of a wide distribution of inter-spike frequencies $(<1$ to $>200 \mathrm{~Hz})$ (Manns et al., 2004; de Kock et al., 2007). The timing, frequency and amplitude of bAPs have strong implications for synaptic and intrinsic plasticity, dendritic electrogenesis, and neuronal output (Frick and Johnston, 2005; Dan and Poo, 2006; Sjöström et al., 2008). This causal relationship between bAPs and information processing/storage led us to explore: (i) the role of AP timing during physiological activity patterns in dendritic signaling; (ii) the reliance of back-propagation efficacy on dendrite type and location; (iii) the postnatal development of this form of dendritic signaling; (iv) the regulation of AP back-propagation by active conductances. To address these questions, we used physiological AP patterns previously recorded in L5A pyramidal neurons in the barrel cortex of anesthetized rats (courtesy of de Kock; de Kock et al., 2007); these firing patterns were replayed in vitro in the same neuron type and brain area, while measuring $\mathrm{Ca}^{2+}$ signals along the main apical, apical tuft, and basal dendrites. 
This work extends previous studies on the frequency dependence of back-propagation in cortical neurons and is, to our knowledge, the first study specifically exploring signal propagation in dendrites of L5A pyramidal neurons. Our data indicate that the changes in instantaneous firing frequency during physiological AP trains have a crucial role for dendritic voltage and biochemical signaling. These findings may have important implications for the induction of dendritic electrogenesis and plasticity.

\section{MATERIALS AND METHODS SLICE PREPARATION AND SOLUTIONS}

Wistar rats (14- to 29-days old) were anesthetized using isoflurane, decapitated, and coronal slices (350- $\mu \mathrm{m}$ thick) were prepared from the 'barrel field' of somatosensory cortex. Experimental procedures were approved by the Animal Research Committee of the Max Planck Society and according to the guidelines laid out in the EU directive on animal welfare. Brain slices were incubated for $20-30 \mathrm{~min}$ at $36^{\circ} \mathrm{C}$ and then stored at room temperature until used. The extracellular solution for cutting and incubation contained (in mM): $125 \mathrm{NaCl}$, $25 \mathrm{NaHCO}_{3}, 2.5 \mathrm{KCl}, 1.25 \mathrm{NaH}_{2} \mathrm{PO}_{4}, 6 \mathrm{MgCl}_{2}, 1 \mathrm{CaCl}_{2}, 3$ myo-inositol, 2 Na-pyruvate, 0.4 ascorbic acid, 25 glucose. For the experiments, brain slices were transferred to the recording chamber and superfused with an extracellular recording solution that contained 125-mM NaCl, 25- $\mathrm{mM} \mathrm{NaHCO}_{3}, 2.5-\mathrm{mM} \mathrm{KCl}, 1.25-\mathrm{mM} \mathrm{NaH}_{2} \mathrm{PO}_{4}$, 1-mM MgCl$, 2-\mathrm{mM} \mathrm{CaCl}_{2}, 25-\mathrm{mM}_{2}$ glucose, and was bubbled with $95 \% \mathrm{O}_{2} / 5 \% \mathrm{CO}_{2}$ (pH 7.4). Recordings were made at near-physiological temperature of $32-36^{\circ} \mathrm{C}$. For the pharmacology experiments, the following drugs were bath-applied (final concentrations): Nimodipine (10 $\mu \mathrm{M}$, Tocris), $\mathrm{Ni}^{2+}\left(100 \mu \mathrm{M}\right.$, Sigma-Aldrich), $\mathrm{Cd}^{2+}$ (500 $\mu \mathrm{M}$, Sigma-Aldrich), paxilline (1 $\mu \mathrm{M}$, Tocris), $\mathrm{Ba}^{2+}(150 \mu \mathrm{M}$, Sigma-Aldrich). Paxilline and nimodipine were dissolved in DMSO at stock concentrations of $1 \mathrm{mM}$ and $10 \mathrm{mM}$, respectively, resulting in a final DMSO concentration of $0.1 \%$.

\section{CELL IDENTIFICATION AND ELECTROPHYSIOLOGY}

The cell layer $5 \mathrm{~A}$ at the border of whisker-related barrel field of the somatosensory cortex was visualized at low magnification $(5 \times)$ under bright-field illumination, and layer 5A pyramidal neurons were visualized with infrared gradient contrast microscopy using a Leica upright microscope, fitted with a $40 \times / 0.8$ numerical aperture water-immersion objective. Recording pipettes (4-6 M $\Omega$ ) were pulled from borosilicate glass and filled with (in $\mathrm{mM}$ ): 135 K-gluconate, 10 HEPES, 10 Phosphocreatine-Na, 4 KCl, 4 ATP-Mg, $0.3 \mathrm{Na}-\mathrm{GTP}, \mathrm{pH} 7.2$ (adjusted with $\mathrm{KOH}$ ). Biocytin $(1.5-2.5 \mathrm{mg} / \mathrm{ml}$, Sigma, Munich, Germany) was added to the recording solution for later identification and morphological reconstruction of the neurons. Signals were recorded using an Axon Instrument amplifier (Axoclamp-2B), low-pass filtered at $3 \mathrm{kHz}$ and sampled at $10-50 \mathrm{kHz}$.

\section{STIMULATION PROTOCOLS}

Stimulation protocols were designed following previous experiments in which trains of action potentials were recorded juxtasomally from L5A pyramidal neurons in the barrel cortex of anesthetized rats (P25-30) in response to primary whisker stimulation. These data were kindly provided by Dr. C. de Kock (Free University of Amsterdam de Kock et al., 2007). These 500 ms-long traces are comprised of spontaneous action potential output and evoked firing (200-ms long whisker stimulation between 145 and 345 ms (for details see de Kock et al., 2007). We tested 10 whisker stimulation episodes from a representative experiment (de Kock, personal communication) containing two to five APs with various ISIs. The absolute time of each action potential during these 500 -ms sequences was taken and a replica trace consisting of $3 \mathrm{~ms}$-long current pulses at the respective time points produced (natural firing pattern). For illustration purposes and to avoid unnecessary duplication, only sequences that substantially differ from each other are shown in the figures. In addition, sequences are arranged in an ascending order of complexity. These natural firing patterns were compared to those evoked by the same number of action potentials presented at the mean frequency (mean firing pattern). Trains of action potentials at these fixed frequencies were generated in the same manner using $3 \mathrm{~ms}$-long current injections.

\section{CALCIUM IMAGING}

The method used for high-resolution, multi-photon imaging of $\mathrm{Ca}^{2+}$ fluorescence was as described previously (Koester et al., 1999). Briefly, we used femtosecond laser pulses at 870-890 nm from a Ti:Sa-Laser (Mira 900F; Coherent, Santa Clara, CA, USA) pumped by a solid-state laser (Verdi $8 \mathrm{~W}$; Coherent), coupled to a galvanometer scanning unit (TCSNT; Leica Microsystems, Mannheim, Germany) that was mounted on an upright microscope (Leica DMLF) equipped with a $40 \times$ objective (HCX APO W40x/0.8 NA). Fluorescence was acquired using external non-descanned detectors (photomultiplier tubes, R6357, Hamamatsu Photonics, Herrsching, Germany) behind the objective and the condenser, yielding a high signal collection efficacy. The $\mathrm{Ca}^{2+}$ signals were recorded in linescan mode with a temporal resolution of $2.2 \mathrm{~ms} /$ line. Recordings of membrane voltage and fluorescence were analyzed offline using commercial software with custom-written algorithms (Igor Pro; WaveMetrics, Lake Oswego, OR, USA). Neurons were filled with a combination of the calcium-sensitive dye Oregon Green 488 BAPTA-I $(200 \mu \mathrm{M})$ or Fluo $5 \mathrm{~F}(200 \mu \mathrm{M})$ and the calcium-insensitive dye Alexa 594 (20-50 $\mu \mathrm{M}$; both dyes from Invitrogen, Carlsbad, CA, USA) added to the intracellular recording solution to visualize the dendritic arbors and measure $\mathrm{Ca}^{2+}$ signals within. Dyes were allowed to fill the neurons for at least $15-20$ min before $\mathrm{Ca}^{2+}$ signals were measured; measurements from the apical tuft region were not taken before at least $45 \mathrm{~min}$ after the soma was patched.

$\mathrm{Ca}^{2+}$ transients are reported as relative changes in OGB-1 fluorescence and were calculated as $\Delta F / F(t)=\left(F(t)-F_{0}\right) /\left(F_{0}-F_{\mathrm{B}}\right)$, where $\mathrm{F}_{0}$ is the baseline fluorescence, taken within $200 \mathrm{~ms}$ before the stimulation and $\mathrm{F}_{\mathrm{B}}$ is the background fluorescence, derived from a non-stained background region. Single exponential fits to the decay of the fluorescence transients were made to calculate the peak amplitude, denoted as transient amplitudes. Fluorescence traces are averages of three to five trials and group data are represented as means \pm sem. Dendritic length constants $\mathrm{L}_{1 / \mathrm{e}}$ of calcium profiles were derived by fitting exponential functions to the profiles, or by taking the value when the profile had dropped to 1/e. GraphPad software Instat 3 and Prism 4 (GraphPad Software, San Diego, CA, USA) was used for statistical analysis. Statistical significance was calculated using paired $t$-tests and non-parametric Mann-Whitney $U$ tests. 


\section{STAINING FOR RECONSTRUCTION}

After recording, biocytin-filled neurons were processed using standard procedures. Slices were fixed at $4^{\circ} \mathrm{C}$ for at least $24 \mathrm{~h}$ in PBS containing $0.4 \%$ paraformaldehyde, then incubated in $0.1 \%$ Triton $\mathrm{X}-100$ solution containing avidin-biotinylated horseradish peroxidase (ABC-Elite; Camon, Wiesbaden, Germany). Subsequently, 3,3-diaminobenzidine was used as reactive chromogen until axons and dendrites were clearly visible (after 2-4 $\mathrm{min}$ ). To enhance staining contrast, slices were occasionally postfixed in $0.5 \% \mathrm{OsO}_{4}$ for 30-40 min before mounting on slides and embedding using Moviol (Clariant, Sulzbach, Germany).

\section{RESULTS}

\section{PHYSIOLOGICAL VERSUS MEAN AP PATTERNS - APICAL DENDRITES}

First, we investigated the role of AP timing within firing patterns in the back-propagation efficacy along apical dendrites. To do this we triggered $500 \mathrm{~ms}$-long physiological firing patterns (de Kock et al., 2007) in L5A pyramidal neurons at P25 and compared them with the corresponding mean firing patterns (same number of APs at mean frequency). While frequencies of the mean firing patterns were always $<20 \mathrm{~Hz}$, physiological firing patterns contained instantaneous frequencies of $>200 \mathrm{~Hz}$. bAP-evoked $\mathrm{Ca}^{2+}$ signals were measured at the soma (apical trunk close to soma), $400-500 \mu \mathrm{m}$ from soma, and in the initial part of the apical tuft ( $\sim 650 \mu \mathrm{m}$ from soma, primary tuft dendrite). For reference, the main branch point (BP) and the tip of the tuft of the L5A apical dendrite at P25 were on average $636 \pm 63 \mu \mathrm{m}$ and $794 \pm 88 \mu \mathrm{m}$ from soma (pia: $845 \pm 89 \mu \mathrm{m}$, mean $\pm \mathrm{SD}, n=10$ ), respectively. The diameters of the dendrites were: $2.7 \pm 0.6 \mu \mathrm{m}$ for apical trunk close to soma, $1.3 \pm 0.2 \mu \mathrm{m}$ for apical dendrite $\sim 400 \mu \mathrm{m}$ from soma, $1.2 \pm 0.1 \mu \mathrm{m}$ for apical dendrite just before major branch point, $0.9 \pm 0.1 \mu \mathrm{m}$ for primary tuft dendrite; $n=5$ ).

The results from one representative experiment at P25 are illustrated in Figure 1. Five selected sequences of physiological firing patterns (out of 10 tested) and the corresponding mean firing patterns are shown in Figure 1B, and the resulting $\mathrm{Ca}^{2+}$ signals are depicted in Figure 1C. A typical finding from our experiments was that at the soma/proximal dendrite both physiological and mean firing patterns evoked strong $\mathrm{Ca}^{2+}$ signals - albeit with very different rise times. In sharp contrast, only three out of ten physiological sequences examined ( 1,3 , and 4 ; none of the mean firing patterns) evoked $\mathrm{Ca}^{2+}$ transients in the distal half of the apical dendrite (and to some extent even the tuft region beyond the BP). A common feature of these specific sequences (also sequence 6) is the occurrence

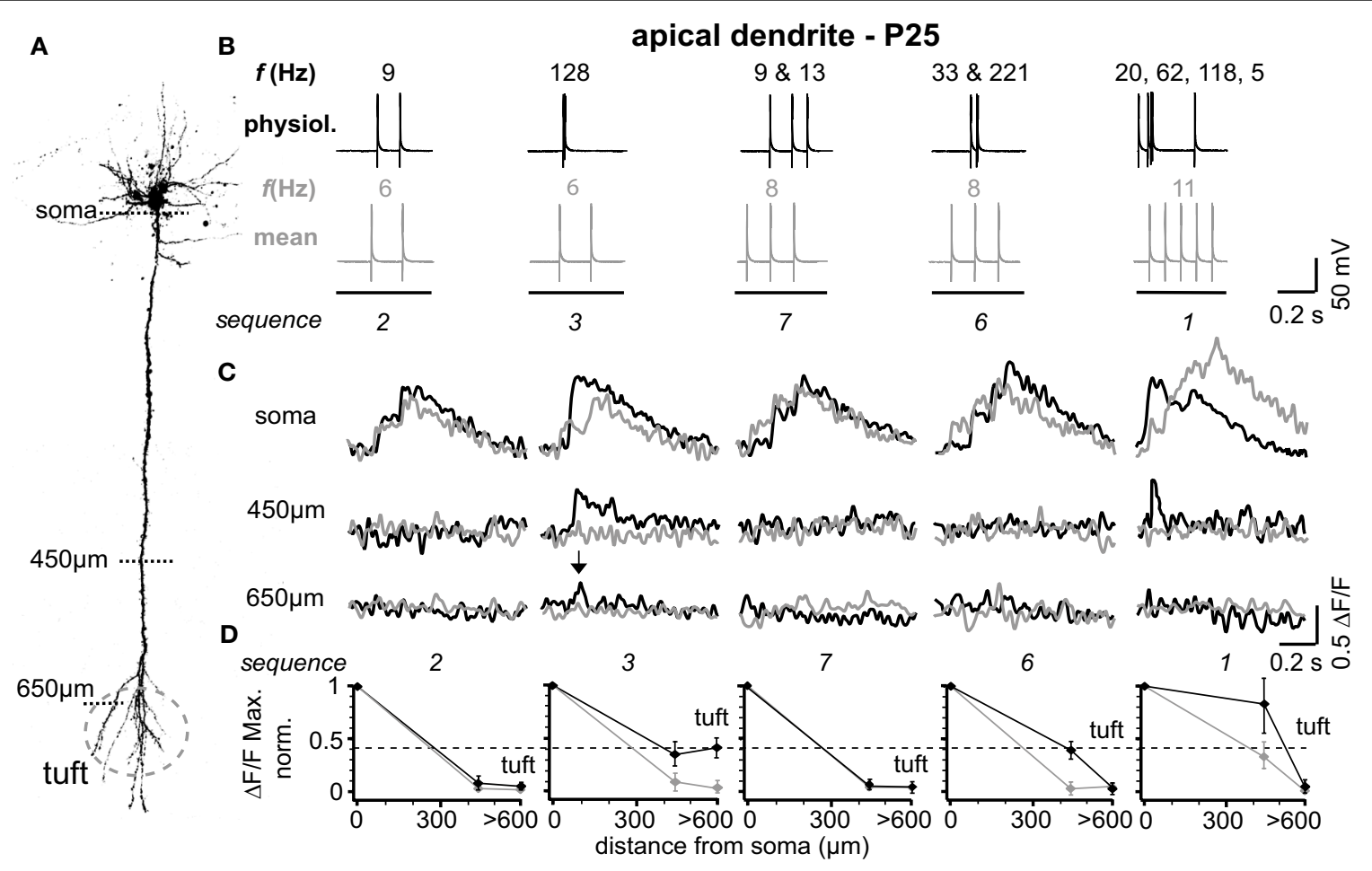

FIGURE 1 | Physiological firing patterns back-propagate more efficiently into the apical arbor than mean firing patterns. (A) Two-photon fluorescence image of a layer $5 \mathrm{~A}$ pyramidal neuron showing the positions of the line-scan $\mathrm{Ca}^{2+}$ measurements. (B) Five (out of ten tested) different physiological firing patterns (black traces) and the corresponding mean firing patterns (gray traces) triggered in a L5A pyramidal neuron at P25. Frequencies within the AP trains are given above the traces. (C) $\mathrm{Ca}^{2+}$ transients were measured at the soma, $450 \mu \mathrm{m}$ from soma, and $650 \mu \mathrm{m}$ from soma (tuft region) (schematic). Note that only AP sequence 3 back-propagated into the distal dendrite (arrows). Fluorescence changes are given as relative changes in the fluorescence of the $\mathrm{Ca}^{2+}$-indicator OGB-1 $(\Delta \mathrm{F} / \mathrm{F})$ and are averages of 3-5 traces. (D) Peak amplitudes of $\mathrm{Ca}^{2+}$ transients ( $\Delta \mathrm{F} / \mathrm{F}$ max, normalized) of physiological and mean firing sequences are plotted as function of distance from soma. Data were measured at the soma, at 400-500 $\mu \mathrm{m}$ and 600$700 \mu \mathrm{m}$ from soma, and are given as mean $\pm \operatorname{sem}(n=9)$ normalized to the soma values. Dashed line indicates the strongest $\mathrm{Ca}^{2+}$ signal in the apical dendritic tuft (sequence 3 ) to emphasize the difference between the physiological and the mean firing pattern. 
of short bursts of two or three APs with short inter-spike intervals (ISIs $<20 \mathrm{~ms}, f>50 \mathrm{~Hz}$ ). The other physiological and all mean firing patterns, in contrast, are comprised of AP sequences of low frequencies (ISIs $\geq 70 \mathrm{~ms}, f<15 \mathrm{~Hz}$ ). The results from nine similar experiments are summarized in Figure 1D. Here, and throughout the manuscript, sample size always refers to number of branches, which is equal to the number of cells. The amplitude of the $\mathrm{Ca}^{2+}$ signals at the soma/proximal dendrite was strongly dependent on both the number, and the ISIs of the AP trains. However, the ISIs became progressively more important for determining $\mathrm{Ca}^{2+}$ signal amplitude with distance from soma. At a distance of 400-500 $\mu \mathrm{m}$ from soma, only AP trains containing high frequency components were capable of eliciting measurable $\mathrm{Ca}^{2+}$ signals. In this region, the peak amplitudes of the $\mathrm{Ca}^{2+}$ signals for sequences containing high-frequency components (sequences 1, 3, 6 and 4 (See Figure 2)) dropped to $\sim 55 \%(0.554 \pm 0.152 \Delta \mathrm{F} / \mathrm{F}$, normalized to soma, $n=9)$, but were significantly larger than those evoked by mean firing patterns $(0.024 \pm 0.008 \Delta \mathrm{F} / \mathrm{F} ; n=9 ; p=0.032)$. Thus, the length constant $\left(\mathrm{L}_{1 / \mathrm{e}}\right)$ for these firing patterns was significantly larger than for the corresponding mean firing patterns $\left(\mathrm{L}_{1 / \mathrm{e}}\right.$ physiological $553 \mu \mathrm{m}+42 /-33 \mu \mathrm{m} ; \mathrm{L}_{1 / \mathrm{e}}$ mean $\left.352 \mu \mathrm{m}+15 /-26 \mu \mathrm{m}\right)$. The $\mathrm{Ca}^{2+}$ transients evoked by sequences 3 and 4 (two APs $\geq 100 \mathrm{~Hz}$ ) were even able to invade the initial part of the apical tuft region beyond the BP $(0.397 \pm 0.043 \Delta \mathrm{F} / \mathrm{F}$ normalized to soma $)$. Within the tuft, however, $\mathrm{Ca}^{2+}$ signals dropped steeply for all firing patterns (see below). Interestingly, sequences 1 and 6 contained high-frequency components but failed to elicit $\mathrm{Ca}^{2+}$ signals in the apical tuft region, perhaps due to their ISI distribution (see Figure 4D).

\section{PHYSIOLOGICAL VERSUS MEAN AP PATTERNS - BASAL DENDRITES}

In L5A pyramidal neurons, basal dendrites comprise approximately $50 \%$ of the total dendritic length (Frick et al., 2008). We therefore examined how well physiological AP output back-propagates into the basal dendrites (Figure 2). Figures 2A,B shows the findings from an individual experiment. $\mathrm{Ca}^{2+}$ transients in response to physiological firing patterns (sequences 1,3,4, and 6) and the corresponding mean firing patterns were recorded at the soma (basal dendrite close to soma, diameter $1.4 \pm 0.2 \mu \mathrm{m}, n=5$ ), at $75 \mu \mathrm{m}$ from soma, and at a distal location of $135 \mu \mathrm{m}$ from soma (diameter at $\sim 120 \mu \mathrm{m}$ from soma $0.7 \pm 0.1 \mu \mathrm{m}$, $n=5$; mean length for basal dendrites $162 \pm 22 \mu \mathrm{m}$, mean $\pm \mathrm{SD}, n=12$, $\mathrm{P} 25)$. Similarly to the apical dendrites, the amplitude of the $\mathrm{Ca}^{2+}$ signals at the proximal basal dendrite was a function of both bAP number and ISIs. In contrast, the short ISIs of the physiological firing patterns did not substantially promote effective back-propagation into the distal half of the dendrite, resulting in comparable $\mathrm{L}_{1 / \mathrm{e}}\left(\mathrm{L}_{1 / \mathrm{e}}\right.$ physiological $96+13 /-21 \mu \mathrm{m}, \mathrm{L}_{1 / \mathrm{e}}$ mean $92+14 /-11 \mu \mathrm{m}$, average of all seven firing sequences, average of all sequences containing at least two APs, $n=6$ ). These experiments demonstrate that the properties of the basal dendrites are very different from those of the apical dendrites.

\section{CRITICAL AP FREOUENCY FOR APICAL DENDRITES}

In vivo, L5A pyramidal neurons of the barrel cortex rarely fire more than two or three APs at higher frequencies - either spontaneously or in response to whisker stimulation (Manns et al., 2004; de Kock et al., 2007). To further examine the critical frequency for efficient back-propagation within this activity range we therefore induced trains of three APs at fixed frequencies ranging from 20 to

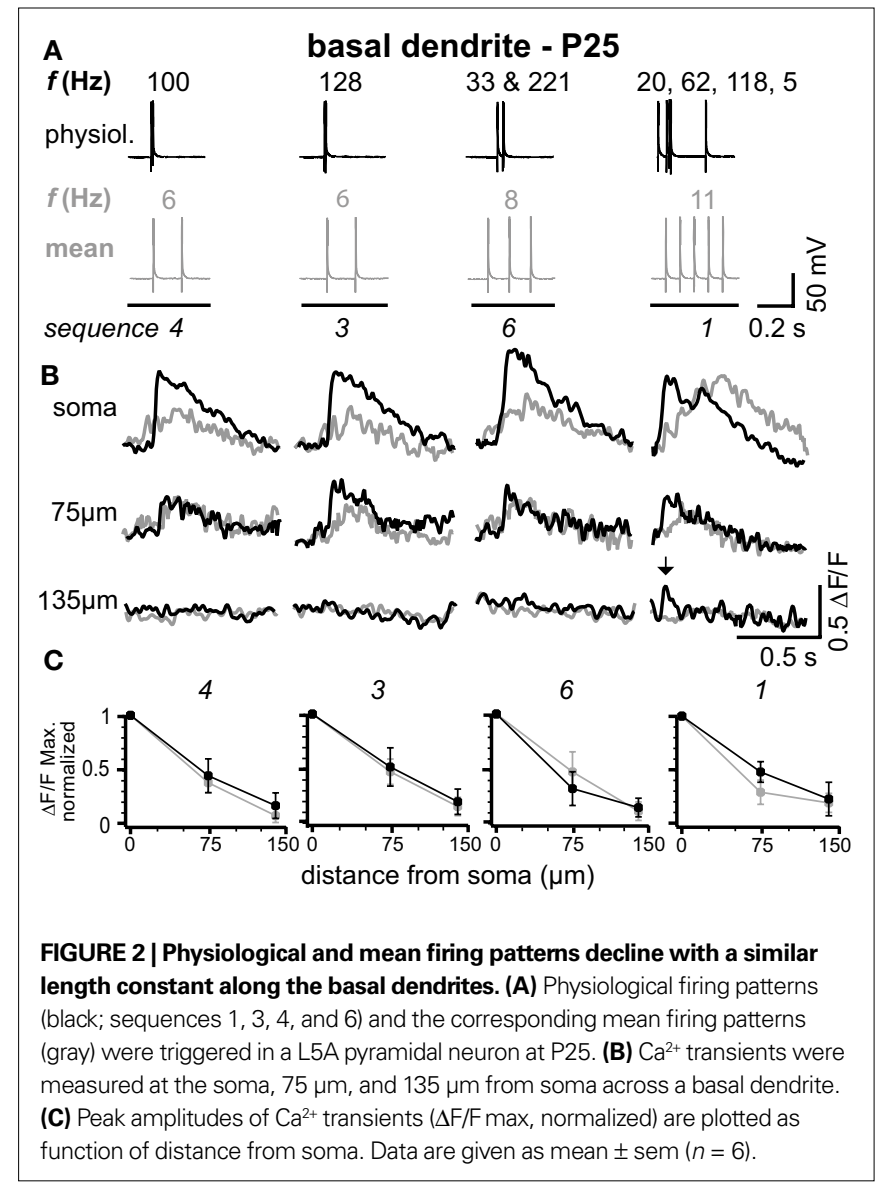

$140 \mathrm{~Hz}$ (Figure 3). The results from one experiment are illustrated in Figure 3B, upper panel, in which $\mathrm{Ca}^{2+}$ signals were measured in the apical dendrite $\sim 530 \mu \mathrm{m}$ from soma. The amplitude of the $\mathrm{Ca}^{2+}$ signal was small at a frequency of $20 \mathrm{~Hz}(0.12 \Delta F / F)$, but strongly increased with higher frequencies, reaching a maximum at $100 \mathrm{~Hz}$ $(0.85 \Delta F / F)$. Surprisingly, frequencies above this critical frequency (CF) evoked smaller transients (not shown). The results from 6 similar experiments are summarized in Figure 3B, lower panel. The CF varied from cell to cell, and was on average $91 \pm 14 \mathrm{~Hz}$ (range $75-140 \mathrm{~Hz}, n=6$ ). The reliance on frequency was strongest in the dendritic region 300-400 $\mu \mathrm{m}$ from soma, were the $\mathrm{Ca}^{2+}$ transients increased substantially when frequencies approached the optimal frequency. In this dendritic region, $\mathrm{Ca}^{2+}$ transients evoked by AP trains at CF were on average $\sim 7$ - to 8-fold larger than those evoked by single APs (normalized to somatic values, $1.32 \pm 0.17 \Delta \mathrm{F} / \mathrm{F}, n=6$, versus $0.18 \pm 0.15 \Delta \mathrm{F} / \mathrm{F}, n=6 ; p=0.0041)$. In summary, higher frequencies $(>40 \mathrm{~Hz})$ were necessary to enable efficient AP backpropagation into the distal half of the apical dendrite.

\section{LACK OF CRITICAL AP FREOUENCY FOR BASAL DENDRITES}

The lack of amplification observed in basal dendrites using physiological AP patterns prompted the question of whether these dendrites possess a critical frequency within the physiological activity range of these neurons. Figure 3C, upper panel, shows the $\mathrm{Ca}^{2+}$ transients elicited in a basal dendrite $\sim 51 \mu \mathrm{m}$ from the soma in response to bursts of three bAPs at varying frequencies. In this 


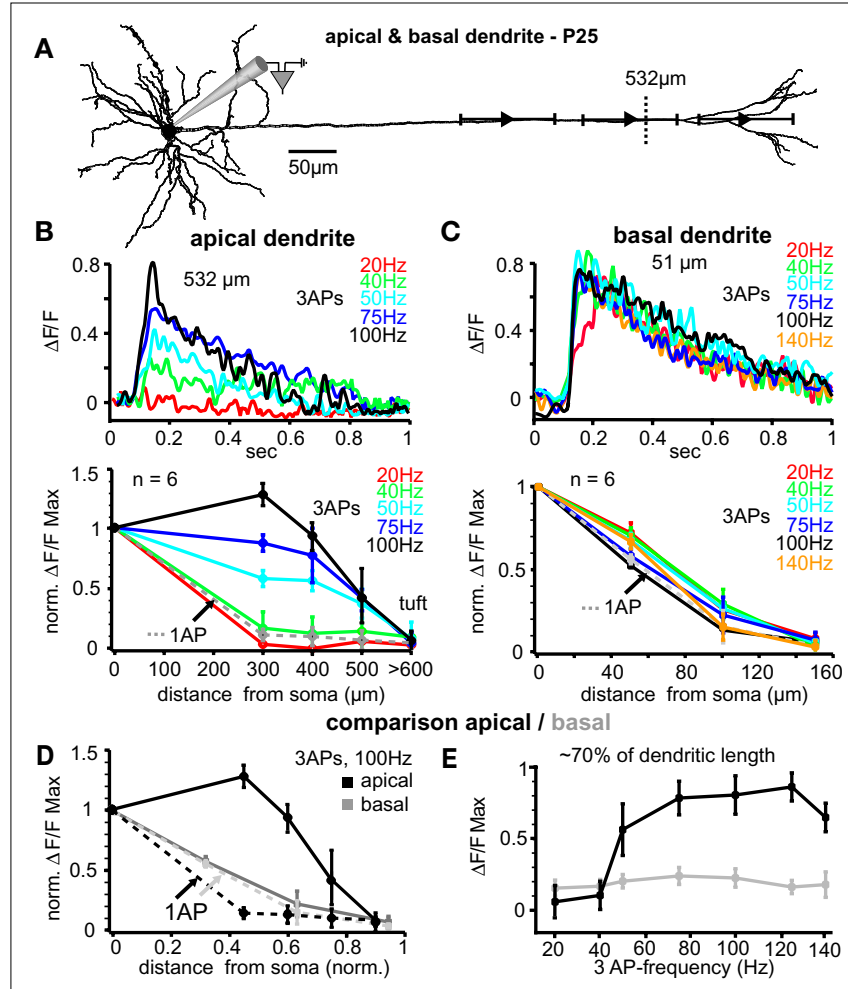

FIGURE 3 | Critical frequency for back-propagation of short AP trains in apical but not basal dendrites. (A) Reconstruction of a L5A pyramidal neuron at P25. $\mathrm{Ca}^{2+}$ measurements were taken at the soma and at three different distances along either the apical dendrite or the basal dendrite (indicated by the symbols and ranges). (B) Apical dendrites, upper panel. $\mathrm{Ca}^{2+}$ transients $(\Delta \mathrm{F} / \mathrm{F})$ evoked by trains of three APs at different fixed frequencies measured at the main apical dendrite $532 \mu \mathrm{m}$ from soma (see dashed line in A) in a P25 L5A pyramidal neuron. Lower panel. Normalized amplitudes of $\mathrm{Ca}^{2+}$ transients evoked by single APs (dashed line) and trains of APs at different frequencies are plotted as function of distance from soma. Average values are mean \pm sem $(n=6)$. (C) Basal dendrites, upper panel. $\mathrm{Ca}^{2+}$ transients $(\Delta \mathrm{F} / \mathrm{F})$ evoked by trains of three APs at different fixed frequencies measured in the basal dendrite $51 \mu \mathrm{m}$ from soma in a P25 L5A pyramidal neuron. Lower panel. Peak $\Delta \mathrm{F} / \mathrm{F} \mathrm{Ca}^{2+}$ signals evoked by single APs and AP trains at different frequencies are normalized and plotted against distance from soma (mean \pm sem, $n=6$ ). Comparison between apical and basal dendrites. (D) Peak $\mathrm{Ca}^{2+}$ signals elicited by single APs and trains of three APs at $100 \mathrm{~Hz}$ were normalized and plotted as function of distance for apical and basal dendrites. Distances were normalized with respect to the total length of these dendrites. (E) $\mathrm{Ca}^{2+}$ transients $(\Delta \mathrm{F} / \mathrm{F}$ max) evoked by three APs are plotted as function of frequency at $70 \%$ of the total basal and apical dendritic length. All data are from P25 neurons.

example (and confirmed in 6 experiments), the $\mathrm{Ca}^{2+}$ signals did not increase as a function of frequency $(20-140 \mathrm{~Hz}$; Figure 3C, lower panel). In 3 cells, frequences of up to $225 \mathrm{~Hz}$ were tested confirming the lack of amplification. Thus, $\mathrm{Ca}^{2+}$ transients of both single bAPs and bAP trains decayed with a similar $\mathrm{L}_{1 / \mathrm{e}}$ of $\sim 90-100 \mu \mathrm{m}$, indicating that there might not be a $\mathrm{CF}$, at least for short bAP trains, in basal dendrites.

\section{COMPARISON OF APICAL AND BASAL DENDRITES}

Our analysis suggests that the dendritic properties determining back-propagation are strikingly different for apical and basal dendrites. Since the length of these dendrite types differs by $\sim 5$-fold

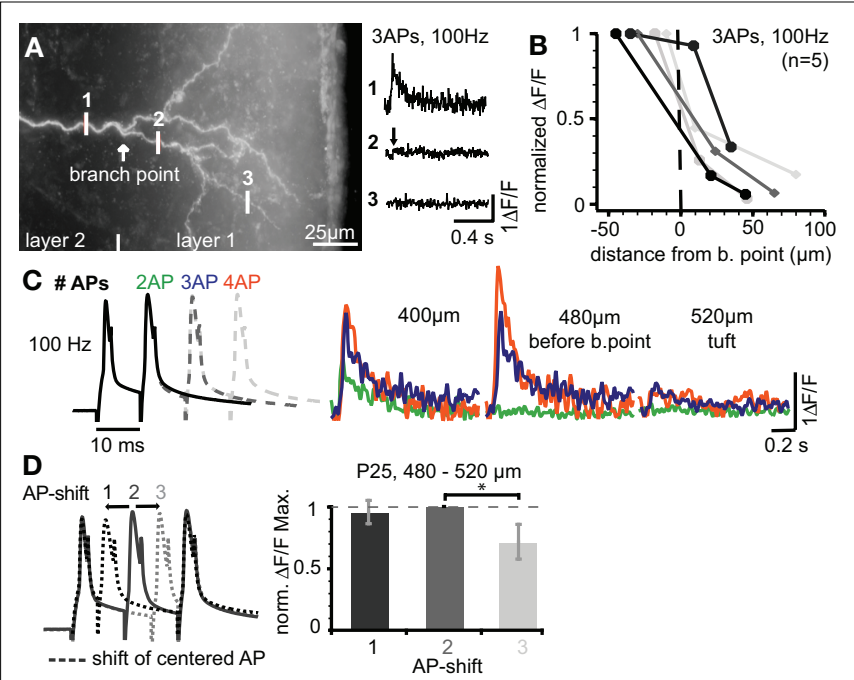

FIGURE 4 | $\mathrm{Ca}^{2+}$ signals steeply drop within the apical dendritic tuft. (A) Photograph of the apical tuft region of a L5A pyramidal neuron indicating the positions for $\mathrm{Ca}^{2+}$ imaging with respect to the major $\mathrm{BP}$. $\mathrm{Ca}^{2+}$ signals were produced by a train of three APs at $100 \mathrm{~Hz}$ and strongly attenuated beyond the $\mathrm{BP}$ (position 2). (B) $\Delta \mathrm{F} / \mathrm{F} \mathrm{Ca}^{2+}$ signals plotted as a function of distance from a position close to the $\mathrm{BP}(n=5)$. (C) $\Delta \mathrm{F} / \mathrm{F} \mathrm{Ca}^{2+}$ signals were evoked by short trains of 2-4 APs at $100 \mathrm{~Hz}$ and measured at three distances before the BP and within the tuft. (D) Dendritic $\mathrm{Ca}^{2+}$ signals depend on changes in instantaneous ISIs. Trains of three APs at $100 \mathrm{~Hz}$ (regular train) were compared with those in which the $2 \mathrm{nd} A \mathrm{P}$ was shifted $\pm 5 \mathrm{~ms}$ in a region $\sim 500 \mu \mathrm{m}$ from soma before the $\mathrm{BP}(n=5) . \Delta \mathrm{F} / \mathrm{F} \mathrm{Ca}^{2+}$ signals were normalized to the regular AP train. Data for this figure were from P14 (A-C) and P25 (D) neurons.

(apical $\sim 800 \mu \mathrm{m}$ versus basal dendrites $\sim 160 \mu \mathrm{m}$ ), we compared back-propagation properties as a function of fractional length (Figures 3D,E). Figure 3D shows the normalized $\mathrm{Ca}^{2+}$ amplitudes evoked by single APs and trains of three APs at $100-\mathrm{Hz}$ along the apical and basal dendrites for six L5A pyramidal neurons. Single bAPs evoked $\mathrm{Ca}^{2+}$ signals that attenuated more strongly along the first $60-70 \%$ of the apical dendrite $\left(\mathrm{L}_{1 / \mathrm{e}}\right.$ apical $272+26 /-19 \mu \mathrm{m}, 0.36$ fractional length, $n=6)$ as compared to basal dendrite $\left(\mathrm{L}_{1 / \mathrm{e}}\right.$ basal $92+30 /-15 \mu \mathrm{m} ; 0.55$ fractional length; $n=6$ ), but failed to produce $\mathrm{Ca}^{2+}$ signals in the distal $30 \%$ of either dendrite type. $\mathrm{Ca}^{2+}$ signals evoked by AP trains at $100 \mathrm{~Hz}$ were significantly increased in the apical dendrites, but not in the basal dendrites (Figures 3D,E; apical dendrite, signal decay to $1 / \mathrm{e}$ of somatic values $596 \pm 53 \mu \mathrm{m}, \sim 0.85$ fractional length; basal dendrite, $\mathrm{L}_{1 / \mathrm{e}} 93+25 /-18 \mu \mathrm{m}, 0.56$ fractional length; $n=6$ ). This analysis strengthens the conclusion that the active properties of basal and apical dendrites are very different.

\section{THE APICAL TUFT REGION AS A SEPARATE DENDRITIC ZONE}

Our previous results indicate that firing patterns containing highfrequency components (e.g. physiological sequences 3 and 4) can reach the apical tuft, but that the $\mathrm{Ca}^{2+}$ signals drop off steeply within the tuft. We set out to investigate back-propagation into the tuft in more detail (Figure 4). Figure 4A shows the tuft region and measurements of the $\mathrm{Ca}^{2+}$ signals produced by three bAPs at $100 \mathrm{~Hz}$ just before the BP (position 1), and at two dendritic sites within the tuft. The $\mathrm{Ca}^{2+}$ signal evoked in the dendrites just before the $\mathrm{BP}$ had almost vanished $\sim 20 \mu \mathrm{m}$ into the tuft region. This strong 
attenuation resulted in a small $\mathrm{L}_{1 / \mathrm{e}}(-30 \mu \mathrm{m}$ starting from position 1 , Figure $4 \mathbf{B}, n=5)$ that was $\sim 3$-fold and $\sim 20$-fold smaller when compared to the basal dendrite $\left(\mathrm{L}_{1 / \mathrm{e}}<100 \mu \mathrm{m}\right)$ and the main apical dendrite $\left(\mathrm{L}_{1 / \mathrm{e}} \sim 600 \mu \mathrm{m}\right)$, respectively. Next, we addressed the question of whether the $\mathrm{Ca}^{2+}$ transients in the tuft depend on the number of bAPs or the AP timing within the bursts. Figure 4C demonstrates that increasing the number of APs within the highfrequency train enhanced the $\mathrm{Ca}^{2+}$ influx within the apical tuft. To probe the reliance of the $\mathrm{Ca}^{2+}$ signals on the AP timing, a regular 3 AP-sequence at $100 \mathrm{~Hz}$ was compared with those, were the 2nd $\mathrm{AP}$ was shifted $\pm 5 \mathrm{~ms}$ (Figure 4D). Sequences containing equal ISIs or a shorter ISI ( $5 \mathrm{~ms}$ ) followed by the longer one $(15 \mathrm{~ms})$ resulted in a comparable $\mathrm{Ca}^{2+}$ influx, whereas the reverse order produced a reduced $\mathrm{Ca}^{2+}$ signal. These data suggest that both the number of APs and the distribution of ISIs within a firing pattern are important factors for the regulation of back-propagation efficacy.

\section{MATURATION OF BACK-PROPAGATION DURING POSTNATAL DEVELOPMENT}

Does the back-propagation efficacy in L5A dendrites change during the postnatal period between P14 and P25? To address this question, physiological and mean firing patterns were triggered in L5A pyramidal neurons at $\mathrm{P} 14$ and the evoked $\mathrm{Ca}^{2+}$ transients were measured along the apical and basal dendrites (Figures 5, 6 and 7C). Similar to P25 dendrites, firing patterns containing highfrequency components substantially improved back-propagation efficacy into the distal half of apical dendrites (Figures 5 and 6), but not basal dendrites (Figure 6).

Figure 7 compares several aspects of back-propagation along the apical dendrite for the two age groups P14 and P25. The CF of AP bursts to induce significant amplification of the $\mathrm{Ca}^{2+}$ signals increased significantly from $55 \pm 9 \mathrm{~Hz}\left(\mathrm{CF}_{\mathrm{p} 14}\right.$, range $40-75 \mathrm{~Hz}$, $n=6, \mathrm{P} 14)$ to $91 \pm 13 \mathrm{~Hz}\left(\mathrm{CF}_{\mathrm{P} 25}\right.$, range $75-140 \mathrm{~Hz}, n=6 ; p=0.036$, P25) (Figure 7A). We also compared the $\mathrm{Ca}^{2+}$ profile for single APs, short AP trains, and for physiological AP patterns along the apical dendrite (Figures 7B,C). Single APs back-propagated more efficiently at P14 compared to P25, whereas the profile for trains of three APs at the respective CFs $\left(\mathrm{CF}_{\mathrm{P} 25}\right.$ and $\left.\mathrm{CF}_{\mathrm{P} 14}\right)$ was more complex. For these AP trains, back-propagation was more efficient along the first half of the dendrite at P25 than at P14, while the reverse was true for the distal half of the dendrite (Figure $7 \mathbf{B}$ ). Physiological firing patterns containing two APs at $\sim \mathrm{CF}_{\mathrm{P} 25}$ backpropagated more efficiently at $\mathrm{P} 25$ (Figure 7C). The $\mathrm{Ca}^{2+}$ profile for the physiological firing sequence 1 (three APs at high frequencies)
A

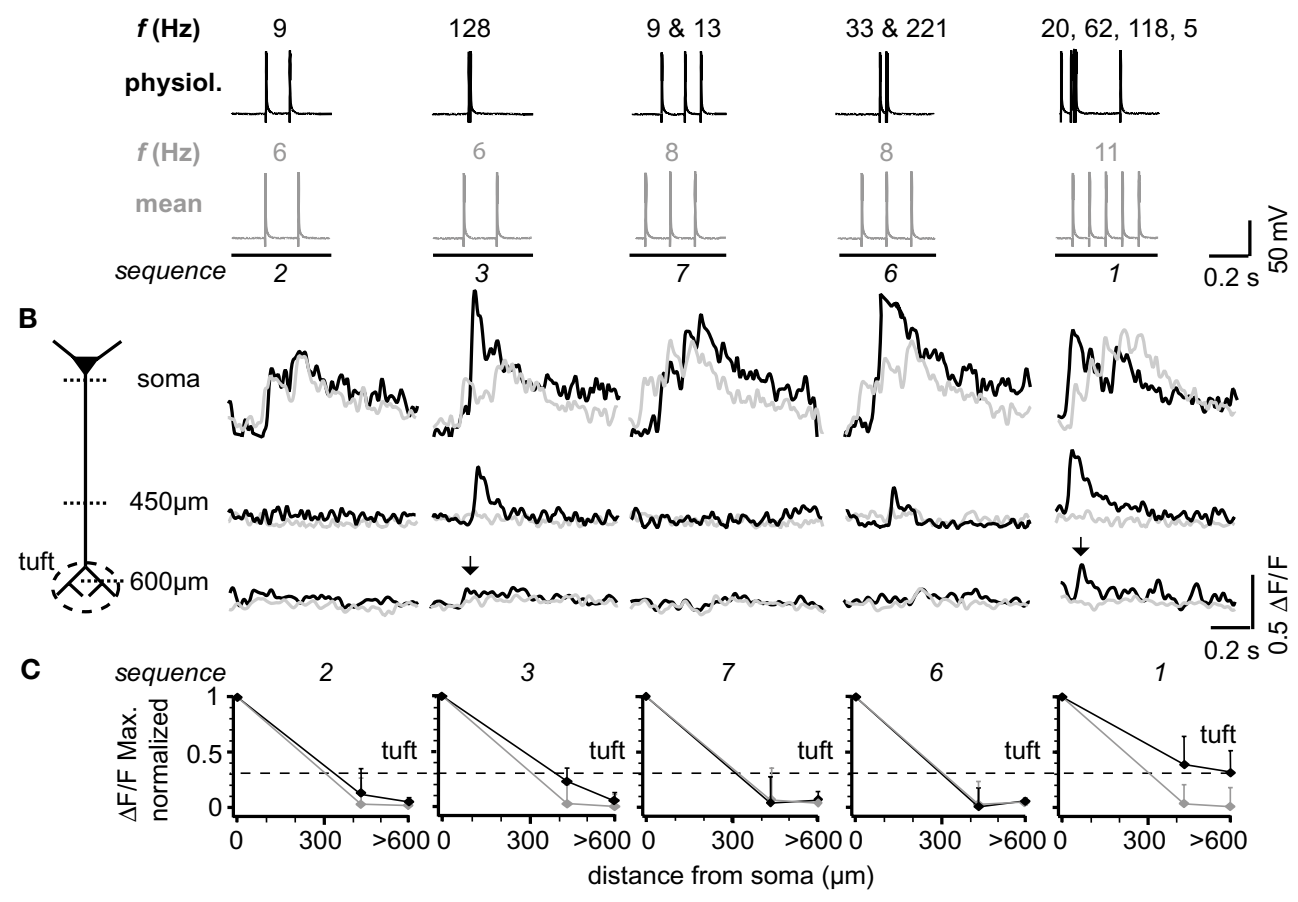

FIGURE 5 | Backpropagation of physiological firing patterns into the apical dendrites at P14. (A) Five (out of ten tested) different natural firing patterns (black traces) and the corresponding mean firing patterns (gray traces) were evoked by somatic current injection in a layer $5 \mathrm{~A}$ pyramidal neuron at P14. Frequencies within the AP trains are given above and the sequence numbers below the traces. (B) $\mathrm{Ca}^{2+}$ transients elicited by these AP sequences were measured at the soma, $450 \mu \mathrm{m}$ from soma, and $650 \mu \mathrm{m}$ from soma (tuft region) across the apical dendritic arbor (see schematic). Note that only AP sequences containing high-frequency components (arrows) back-propagate into the distal half of the apical dendritic arbor. Fluorescence changes are given as relative changes in the fluorescence of the $\mathrm{Ca}^{2+}$-indicator OGB-1 $(\Delta \mathrm{F} / \mathrm{F})$ and are averages of 3-5 traces. (C) Peak amplitudes of $\mathrm{Ca}^{2+}$ transients $\left(\Delta \mathrm{F} / \mathrm{F}_{\mathrm{Max}^{\prime}}\right.$ normalized) of natural and mean firing sequences are plotted as function of distance from soma. Data were measured at the soma, at a region 400 to $500 \mu \mathrm{m}$ from soma, and at a region 600 to $700 \mu \mathrm{m}$ from soma, and are given as mean $\pm \operatorname{sem}(n=9)$ normalized to the soma values. Dashed line indicates the strongest $\mathrm{Ca}^{2+}$ signal that could be evoked in the apical dendritic tuft (sequence 1) to emphasize the difference between the natural and the mean firing pattern. 


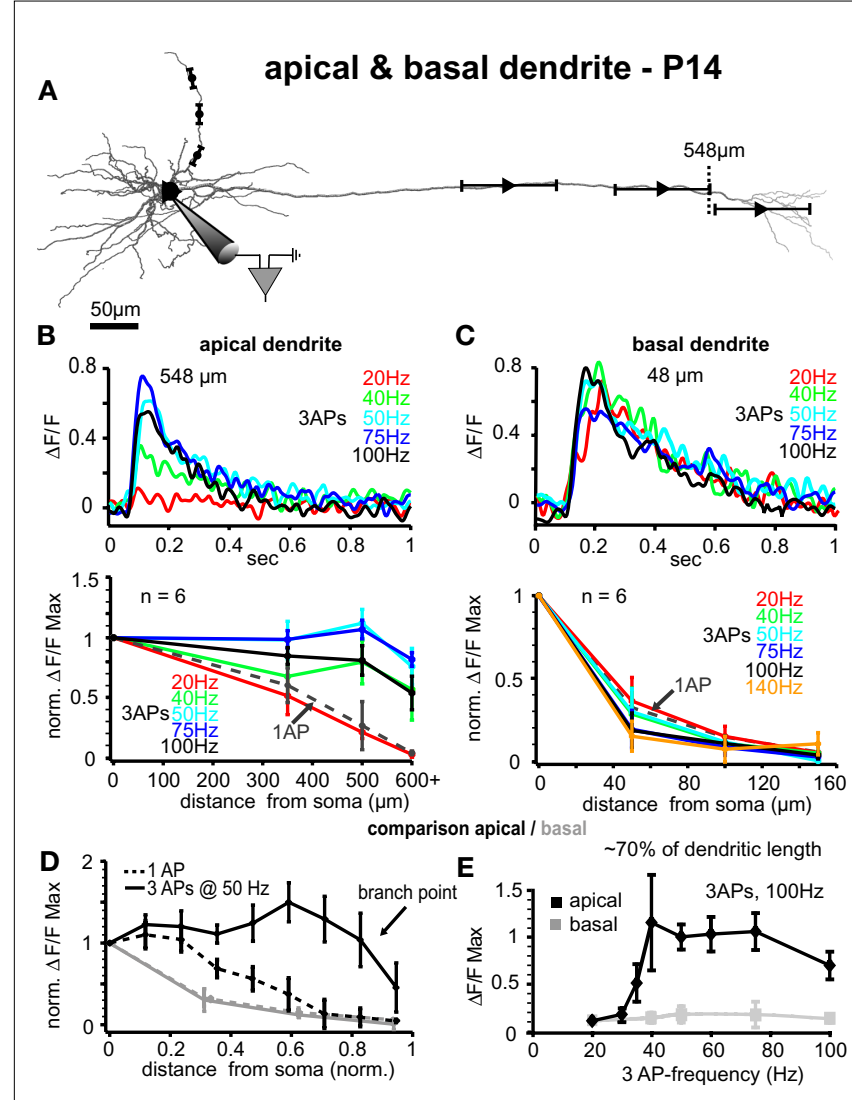

FIGURE 6 | Comparison between apical and basal dendrites at P14. (A) Reconstruction of a L5A pyramidal neuron at P14. Trains of three APs were evoked by current injections into the soma and calcium measurements were taken at the soma and at three different distances along either the apical dendrite or the basal dendrite (indicated by the symbols and ranges). (B) Apical dendrites, upper panel. $\mathrm{Ca}^{2+}$ transients $(\Delta F / F)$ evoked by trains of three APs at different fixed frequencies measured at the main apical dendrite close to the major branch point (548 $\mu \mathrm{m}$ from soma, see arrow) in a P14 L5A pyramidal neuron. Frequencies ranged from $20 \mathrm{~Hz}$ to $100 \mathrm{~Hz}$. Note that the maximal response was evoked at 50 $\mathrm{Hz}$. Lower panel. Peak amplitudes of $\mathrm{Ca}^{2+}$ transients $(n=6)$ evoked by trains of three APs at different frequencies are normalized to the somatic values and plotted as function of distance from soma. For comparison, $\mathrm{Ca}^{2+}$ transients evoked by single APs (dashed line) are also shown. Average values are mean \pm sem. Note that the frequency is becoming increasingly important at distances from soma more distal than $300 \mu \mathrm{m}$, and that signals drop off steeply beyond the major branch point within the apical tuft. (C) Basal dendrites, upper panel. $\mathrm{Ca}^{2+}$ transients $(\Delta \mathrm{F} / \mathrm{F})$ evoked by trains of three APs at different fixed frequencies measured at the basal dendrite $\sim 50 \mu \mathrm{m}$ from soma in a P14 L5A pyramidal neuron. Frequencies ranged from 20 to $100 \mathrm{~Hz}$. Lower panel. Peak $\Delta F /$ $\mathrm{F} \mathrm{Ca}^{2+}$ signals evoked by single APs and short trains of three APs at different fixed frequencies ranging from 20 to $140 \mathrm{~Hz}$ are normalized and plotted against distance from soma along the basal dendrites $(n=6)$. Note that there is no significant difference in the efficacy of back-propagation within this frequency range. (D,E) Comparison of apical versus basal dendrites. (D) Peak $\mathrm{Ca}^{2+}$ signals elicited by single APs and trains of three APs at $50 \mathrm{~Hz}$ were normalized and plotted as function of distance from soma. Distances along the basal and apical dendrites were normalized with respect to the total length of the dendrites to enable comparison of back-propagation efficacy across different dendrite compartments. Note the significant differences in back-propagation for apical and basal dendrites. (E) Differences in frequency-dependence are compared for a normalized distance of $\sim 70 \%$ along the basal $(80-100 \mu \mathrm{m})$ and apical (400$500 \mu \mathrm{m})$ dendrites. $\mathrm{Ca}^{2+}$ signals evoked by trains of three APs at different frequencies were normalized to the $20-\mathrm{Hz}$ train. Note the steep amplification in $\mathrm{Ca}^{2+}$ influx at the apical dendrite with increasing frequency.

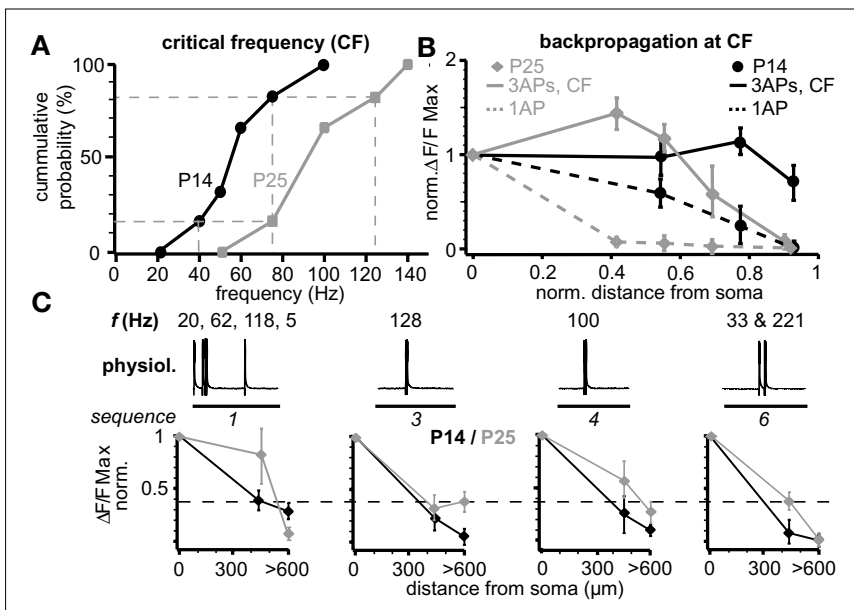

FIGURE 7 | Maturation of back-propagation during postnatal

development. (A) Cumulative probability plot of the CFs for short trains of three APs for layer 5 A pyramidal neurons at P14 and P25 ( $n=6$ for each age group). Dashed lines indicate the CF-ranges from $40-75 \mathrm{~Hz}$ at P14 and

$75-125 \mathrm{~Hz}$ at P25 (corresponding to $1 / 6$ and $5 / 6$ of cumulative probability). (B) Normalized (to soma) peak $\triangle \mathrm{F} / \mathrm{F} \mathrm{Ca}^{2+}$ signals evoked by single APs and bursts of three APs at the respective CF at P14 $(60-75 \mathrm{~Hz})$ and P25 $(100-125 \mathrm{~Hz}$ ) as function of normalized distance from soma (mean $\pm \mathrm{sem}, n=6$ for each age group). (C) Normalized peak $\Delta \mathrm{F} / \mathrm{F} \mathrm{Ca}^{2+}$ signals of physiological firing patterns (sequences 1, 3, 4, and 6) as function of distance from soma for P14 and P25 L5A pyramidal neurons (mean \pm sem, $n=9$ for each age group).

matched the profile for trains of three APs at high frequencies, i.e. the $\mathrm{Ca}^{2+}$ signals produced in the distal dendrite were larger for P14 than P25.

\section{DENDRITIC ELECTROGENESIS INVOLVES THE RECRUITMENT OF DIFFERENT $\mathrm{CA}^{2+}$ AND $\mathrm{K}^{+}$CHANNELS}

Next, we probed the role of voltage-gated ion channels in the $\mathrm{Ca}^{2+}$ influx during AP back-propagation in the apical dendrites 300$400 \mu \mathrm{m}$ from soma at P25. Specifically, we tested the involvement of $\mathrm{Ca}^{2+}$ channels (L-type, T-/R-type, all types), large-conductance $\mathrm{Ca}^{2+}$-dependent $\mathrm{K}^{+}$channels $\left(\mathrm{BK}_{\mathrm{Ca}}\right)$, and transient A-type $\mathrm{K}^{+}$channels (Figure 8). Single bAPs, as well as bursts of three bAPs above $(100 \mathrm{~Hz})$ and below $(20 \mathrm{~Hz}) \mathrm{CF}$ were triggered while measuring the resulting $\mathrm{Ca}^{2+}$ transients. The application of $10-\mu \mathrm{M}$ nimodipine to block L-type $\mathrm{Ca}^{2+}$ channels reduced the $\mathrm{Ca}^{2+}$ transient evoked by the $100-\mathrm{Hz}$ bAP burst by $\sim 15 \%(0.85 \pm 0.07, n=5, p=0.041$; Figures 8A,B). Blockade of T-/R-type $\mathrm{Ca}^{2+}$ channels by application of $100-\mu \mathrm{M} \mathrm{Ni}^{2+}$ reduced the remaining transient by $\sim 20 \%(0.68 \pm 0.12$, $n=5, p=0.044)$. Further addition of $500-\mu \mathrm{M} \mathrm{Cd}^{2+}$ completely blocked the $\mathrm{Ca}^{2+}$ transient $(0.038 \pm 0.025, n=5, p=0.007)$. The specific $\mathrm{BK}_{\mathrm{Ca}}$ blocker paxilline $(1 \mu \mathrm{M})$ significantly increased the $\mathrm{Ca}^{2+}$ transient associated with the $100-\mathrm{Hz}$ AP burst $(2.44 \pm 0.45$, median 2.51, $n=4, p=0.011$; Figures 8C,D). Similarly, blocking A-type $\mathrm{K}^{+}$channels by low concentrations of $\mathrm{Ba}^{2+}(150 \mu \mathrm{M}$, specific for this channel at this concentration) increased the $\mathrm{Ca}^{2+}$ transient (1.46 \pm 0.16 , median $1.29, n=5, p=0.0185)$.

Single bAPs and low-frequency $(20 \mathrm{~Hz})$ bursts of three bAPs produced little or no $\mathrm{Ca}^{2+}$ signal $300-400 \mu \mathrm{m}$ from soma, preventing us from examining $\mathrm{Ca}^{2+}$ channel contribution. Thus, only the effects of blockers on $\mathrm{BK}_{\mathrm{Ca}}$ channels and A-type $\mathrm{K}^{+}$channels were quantified. 


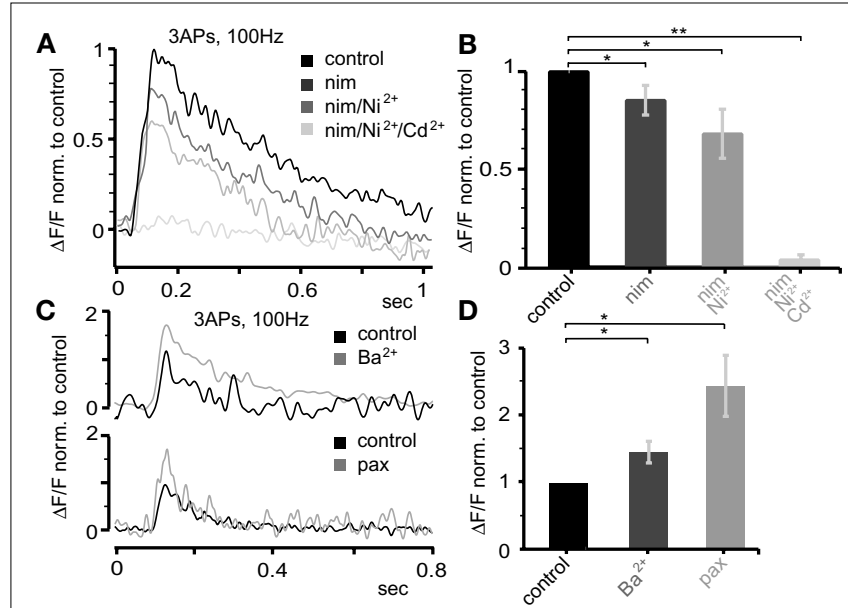

FIGURE 8 | Dendritic electrogenesis is regulated by $\mathbf{C a}^{2+}$ and $\mathrm{K}^{+}$channels. (A) Effect of the following $\mathrm{Ca}^{2+}$ channel blockers on $\mathrm{Ca}^{2+}$ signals $(\Delta \mathrm{F} / \mathrm{F})$ evoked by trains of three APs at $100 \mathrm{~Hz}$ at the apical dendrite $425 \mu \mathrm{m}$ from soma in a P25 neuron: nimodepine (nim, $10 \mu \mathrm{M}$, L-type), $\mathrm{Ni}^{2+}(100 \mu \mathrm{M}, \mathrm{T}-/ \mathrm{R}$-type), and $\mathrm{Cd}^{2+}\left(500 \mu \mathrm{M}\right.$, all Ca ${ }^{2+}$ channels). All traces were normalized to the control trace. (B) Group data for the effect of $\mathrm{Ca}^{2+}$ channel blockers (normalized to control, mean \pm sem, $n=5)$. (C) Effect of $\mathrm{BK}_{\mathrm{Ca}}\left(1 \mu \mathrm{M}\right.$ paxilline) and A-type $\mathrm{K}^{+}$ $\left(150 \mu \mathrm{M} \mathrm{Ba}^{2+}\right)$ channel blockers on the $\mathrm{Ca}^{2+}$ signals produced by bursts of three APs at $100 \mathrm{~Hz} 300-400 \mu \mathrm{m}$ from soma in the apical dendrite in P25 neurons.

(D) Average data (mean \pm sem) from nine similar experiments $\left(n_{\mathrm{Ba}}=5\right.$, $\left.n_{\text {Pax }}=4\right)$ normalized to control. All data are from P25 neurons.

In contrast to high-frequency bursts, $20-\mathrm{Hz}$ bursts caused only a moderate activation of $\mathrm{BK}_{\mathrm{Ca}}$ channels $(1 \mu \mathrm{M}$ paxilline, $1.34 \pm 0.35$, median 1.47, $n=4, p=0.513)$. On the contrary, A-type $\mathrm{K}^{+}$channels significantly suppressed $\mathrm{Ca}^{2+}$ transients evoked under those conditions ( $150 \mu \mathrm{M} \mathrm{Ba}^{2+}, 3.85 \pm 0.93$, median 3.32, $\left.n=6, p=0.0134\right)$.

\section{DISCUSSION}

Our major conclusion is that the temporal composition of physiological firing patterns consisting of variable instantaneous frequencies determines back-propagation efficacy of the apical dendritic arbor. Specifically, we found that even two APs at CF significantly increase the amplitude of $\mathrm{Ca}^{2+}$ influx into the distal half (excluding the tuft region) of L5A apical dendrites. This CF shifted during early postnatal maturation from $\sim 55 \mathrm{~Hz}$ at $\mathrm{P} 15$ to $\sim 90 \mathrm{~Hz}$ at P25. In contrast, mean firing patterns with frequencies of $<20 \mathrm{~Hz}$ back-propagated inefficiently into the distal apical dendrites. Furthermore, we show that the rules governing back-propagation are dendrite type-specific, in that there was no comparable amplification in back-propagation observed for the basal dendrites or the tuft region of the apical arbor. We also examined the role of various voltage-gated ion channels in regulating back-propagation during these different activity regimes. To our knowledge, this is the first study investigating the active properties of L5A pyramidal neuron dendrites, and our data further underline the importance of studying neuronal properties in a manner that reflects the activity of the specific cell type under investigation.

\section{VALIDITY OF STUDYING BACK-PROPAGATION IN VITRO}

Neocortical brain slices exhibit a lower synaptic background activity than that occurring in vivo. In spite of this, several studies demonstrate that the amplitude of bAPs in L2/3 and L5B pyramidal neurons is similar in vivo and in vitro (Helmchen et al., 1999; Larkum and Zhu, 2002; Waters et al., 2003; Bereshpolova et al., 2007; Bar-Yehuda and Korngreen, 2008). Together, this work supports the idea that bAPs are a robust and reliable property of pyramidal neurons during different states of network activity.

\section{EFFECTIVE BACK-PROPAGATION INTO THE APICAL DENDRITES DURING PHYSIOLOGICAL AP PATTERNS}

We show that, in L5A pyramidal neurons, low-frequency $(\leq 20 \mathrm{~Hz})$ AP firing fails to efficiently invade the distal half of the apical dendritic arbor. In contrast, efficient back-propagation is evoked by physiological or regular AP patterns containing higher frequencies, particularly at the CF (Figures 1, 3 and 5-7). Since bAPs are important in a variety of neuronal processes (including STDP; Magee and Johnston, 1997; Markram et al., 1997; Dan and Poo, 2006), the induction of intrinsic plasticity; Frick et al., 2004 and local synaptic integration; Larkum et al., 1999; Stuart and Hausser, 2001), efficient back-propagation during physiological firing patterns will also determine the rules for information processing and storage (Frick and Johnston, 2005; Dan and Poo, 2006; Sjöström et al., 2008).

\section{COMPARISON BETWEEN APICAL, BASAL, AND TUFT DENDRITES}

In contrast to the main apical dendrites, neither physiological firing patterns nor short high frequency bursts of APs are able to enhance back-propagation into the $5 \mathrm{~A}$ basal dendrites. As a result, the degree of attenuation $\left(\mathrm{L}_{1 / \mathrm{e}}\right)$ for high-frequency AP bursts is approximately 6-fold higher for basal compared to apical dendrites (Figure 3D). In the apical tuft, in contrast to the main apical and basal dendrites, no $\mathrm{Ca}^{2+}$ influx is produced by low frequency firing (Figures 1,3 and 5). Even physiological AP patterns/regular AP trains containing CF components produce only small $\mathrm{Ca}^{2+}$ transients that drop steeply beyond the BP $\left(\mathrm{L}_{1 / \mathrm{e}} \sim 30 \mu \mathrm{m}\right.$ for three APs at $100 \mathrm{~Hz}$, Figure 4). Differences in back-propagation properties between main apical, apical tuft, and basal dendrites may reflect differences in the expression levels and/or types of voltage-dependent conductances, and in the dendritic morphology.

\section{COMPARISON WITH L2/3 AND L5B PYRAMIDAL NEURONS Back-propagation in apical dendrites}

Our data suggest that for low-frequency $(\leq 20 \mathrm{~Hz})$ firing, backpropagation in L5A pyramidal neurons is more efficient than in L2/3 pyramidal neurons but weaker compared with L5B pyramidal neurons (Schiller et al., 1995; Larkum, 1999; Waters et al., 2003; Larkum et al., 2007). An amplification in the $\mathrm{Ca}^{2+}$ signals by high-frequency bAP firing has been previously described for both L2/3 and L5B pyramidal neurons (Larkum, 1999; Williams and Stuart, 2000; Waters et al., 2003). The CF for efficient backpropagation reported here for L5A pyramidal neurons $(\sim 90 \mathrm{~Hz})$ is either slightly smaller (L2/3, $\sim 130 \mathrm{~Hz}$; Larkum et al., 2007) or similar (L5B, $\sim 100 \mathrm{~Hz}$; Larkum, 1999) compared with these neurons.

\section{Back-propagation in basal dendrites}

In contrast to $\mathrm{L} 5 \mathrm{~A}, \mathrm{Ca}^{2+}$ transients evoked by single bAPs do not attenuate along the basal dendrites of L5B pyramidal neurons (Kampa and Stuart, 2006; Nevian et al., 2007), and regenerative 
$\mathrm{Ca}^{2+}$ influx may or may not be recruited by high-frequent AP activity in these neurons (Kampa and Stuart, 2006; Nevian et al., 2007). In L5A pyramidal neurons, we did not observe a significant increase in the $\mathrm{Ca}^{2+}$ transients of basal dendrites within the physiological activity range (Manns et al., 2004; Frick et al., 2007; de Kock and Sakmann, 2009) for these neurons.

\section{Back-propagation into the distal tuft}

Similar to the results obtained for L2/3 neurons (Waters et al., 2003), but in contrast to those from L5B (Schiller et al., 1995; Larkum, 1999), single APs and short low-frequency AP patterns failed to produce $\mathrm{Ca}^{2+}$ signals in the tuft beyond the major BP. High-frequency AP patterns, on the other hand, evoked small $\mathrm{Ca}^{2+}$ signals within the tuft (similar to L2/3 pyramidal neurons for comparable AP numbers) (Waters et al., 2003). These signals, however, were strongly attenuated along the primary tuft dendrites with $\mathrm{L}_{1 / \mathrm{e}}$ of $\sim 30 \mu \mathrm{m}$ from major BP (three APs at $100 \mathrm{~Hz}$ ). This attenuation was much more pronounced than that observed in the primary tuft dendrites of L5B pyramidal neurons (Larkum, 1999), and more similar to that recorded in the higher-order tuft branches in these neurons (Helmchen et al., 1999; Larkum and $\mathrm{Zhu}, 2002$ ). One explanation for these findings is that the primary tuft dendrites of L5A pyramidal neurons contain a lower density of active conductances, resulting in a more passive membrane and an increase in the threshold for dendritic electrogenesis. It is possible that $\mathrm{Ca}^{2+}$ spikes in the tuft dendrites can be evoked by the coincidence of bAPs and synaptic input, thereby increasing the gain of these neurons.

\section{AP FIRING PATTERNS AND DENDRITIC ELECTROGENESIS}

The variability in AP timing of physiological activity patterns could convey important information, reflecting the precise integration of spatio-temporal patterns of synaptic inputs; alternatively, this irregularity may reflect noise and information could be represented by mean firing rates recorded over hundreds of milliseconds (Mainen et al., 1995; Shadlen and Newsome, 1995; Nowak et al., 1997; Stevens and Zador, 1998; Ahissar et al., 2000; Panzeri et al., 2001). Our study shows that the efficacy of AP back-propagation along L5A apical dendrites strongly correlates with the distribution of instantaneous ISIs during physiological activity patterns. These data lend support to the idea that the temporal structure of physiological firing patterns may contain important information for dendritic signaling and plasticity (Williams and Stuart, 2000). Short bursts of action potentials in physiological spike trains have been suggested to transmit significant informational content (reviewed in Lisman, 1997).

\section{ION CHANNELS REGULATING AP BACK-PROPAGATION}

It was hitherto unknown which active conductances shape AP back-propagation in L5A pyramidal neurons. In L5B pyramidal neurons, low-voltage (T-type) and high-voltage (L- and N-type) $\mathrm{Ca}^{2+}$ channels, A-type $\mathrm{K}^{+}$channels, and $\mathrm{BK}_{\mathrm{Ca}}$ channels are present in the apical dendrites (Migliore and Shepherd, 2002; Benhassine and Berger, 2005). We found that low- and high-voltage $\mathrm{Ca}^{2+}$ channels (T-/R-, L-, and others) are activated in the apical dendrites of L5A neurons during regimes of high frequency AP activity. Our results also demonstrate that A-type $\mathrm{K}^{+}$channels strongly dampen den- dritic excitability, both during low- and high-frequent AP activity, in agreement with findings from hippocampal CA1 pyramidal neurons (e.g. Hoffman et al., 1997; Frick et al., 2003). BK $\mathrm{Ca}$ channels and A-type $\mathrm{K}^{+}$channels significantly dampened the highfrequency bAP burst-evoked $\mathrm{Ca}^{2+}$ signals. In contrast to A-type $\mathrm{K}^{+}$ channels, however, $\mathrm{BK}_{\mathrm{Ca}}$ channels were not significantly activated by single bAPs or low-frequency bAP bursts. This is consistent with a recent study showing that $\mathrm{BK}_{\mathrm{Ca}}$ channels increase the threshold for dendritic electrogenesis (Benhassine and Berger, 2009), but that their activation requires a large $\mathrm{Ca}^{2+}$ influx (Benhassine and Berger, 2005). Our results are a first step in determining the source of $\mathrm{Ca}^{2+}$ signals, and the ion channels that dampen dendritic excitability in the dendrites of L5A pyramidal neurons.

\section{DEVELOPMENTAL CHANGE IN AP BACK-PROPAGATION}

Our results show that the profile of AP-associated $\mathrm{Ca}^{2+}$ signals along the apical dendrites changes during postnatal development. For the apical dendrites, the attenuation of $\mathrm{Ca}^{2+}$ signals evoked by single APs and low-frequency $(\leq 20 \mathrm{~Hz})$ AP trains increased with age. Physiological AP patterns containing high-frequency components (mostly two APs, e.g. sequences 3,4, and 6), however, propagated more efficiently towards the distal dendrite at P25 compared with P14. $\mathrm{Ca}^{2+}$ signals evoked by trains of three APs at fixed frequencies suggest that at P25 the largest amplification occurs in more proximal dendritic regions $(-300 \mu \mathrm{m})$ when compared with P14 $(\sim 500 \mu \mathrm{m})$. In contrast to most physiological AP patterns, but similar to sequence 1 (three APs at high frequencies), these signals attenuated more strongly within the distal half of the dendrite than at P14. This suggests that at P14 an additional AP has a larger amplifying effect on back-propagation than at $\mathrm{P} 25$. We also observed an increase in the CF from $\sim 55$ to $\sim 90 \mathrm{~Hz}$ between P14 and P25 days of postnatal development. For the basal dendrites, $\mathrm{AP}-\mathrm{Ca}^{2+}$ signal attenuation was more pronounced at P14 than at P25, and no amplification was observed for the activity patterns tested at both ages. The most plausible explanation for these changes in dendritic excitability during development is a change in the expression levels of active conductances in the dendrites (Hamill et al., 1991; Zhu, 2000; Atkinson and Williams, 2009).

In summary, we conclude that the active dendritic properties of L5A pyramidal neurons strongly depend on the age and the type of dendrite - setting up largely different rules for information processing and plasticity in the main apical, apical tuft, and basal dendrites, respectively. Accordingly, these different dendritic arbors will have branch specific rules for the propagation of physiologically occurring action potential output and for its coupling with synaptic input. In this way, these different rules could improve the storage and processing capabilities of L5A pyramidal neurons. Lastly, our study supports the idea that the different role L5A and L5B pyramidal neurons play within the neocortical circuitry is established by their distinct morphological, connectivity, and now dendritic criteria.

\section{ACKNOWLEDGMENTS}

The authors wish to thank Drs. F. Helmchen, B. Kampa, and M. Ginger for valuable comments on the manuscript, Mrs. M. Kaiser and E. Stier for technical assistance, and Dr. C. de Kock for providing 
the in vivo L5A activity data. Part of this work was performed at the Cellular Imaging Facility (PICIN) at the Neuroscience Institute, Bordeaux. Research supported by the Max Planck Society, an
AVENIR grant of the Institut National de la Santé et de la Recherche Médicale (INSERM), and the Network of European Neuroscience Institutes (ENI-Net).

\section{REFERENCES}

Ahissar, E., Sosnik, R., and Haidarliu, S. (2000). Transformation from temporal to rate coding in a somatosensory thalamocortical pathway. Nature 406, 302-306.

Antic, S. D. (2003). Action potentials in basal and oblique dendrites of rat neocortical pyramidal neurons. J. Physiol. (Lond.) 550, 35-50.

Atkinson, S. E., and Williams, S. R. (2009). Postnatal development of dendritic synaptic integration in rat neocortical pyramidal neurons. J. Neurophysiol. 102, 735-751.

Bar-Yehuda, D., and Korngreen, A. (2008). Space-clamp problems when voltage clamping neurons expressing voltagegated conductances. J. Neurophysiol. 99, 1127-1136.

Benhassine, N., and Berger, T. (2005). Homogeneous distribution of largeconductance calcium-dependent potassium channels on soma and apical dendrite of rat neocortical layer 5 pyramidal neurons. Eur. J. Neurosci. 21, 914-926.

Benhassine, N., and Berger, T. (2009). Large-conductance calciumdependent potassium channels prevent dendritic excitability in neocortical pyramidal neurons. Pflugers Arch. 457, 1133-1145.

Bereshpolova, Y., Amitai, Y., Gusev, A., Stoelzel, C., and Swadlow, H. (2007). Dendritic backpropagation and the state of the awake neocortex. J. Neurosci. 27, 9392-9399.

Bernard, C., and Johnston, D. (2003). Distance-dependent modifiable threshold for action potential backpropagation in hippocampal dendrites. J. Neurophysiol. 90, 1807-1816.

Brecht, M. (2002). Dynamic representation of whisker deflection by synaptic potentials in spiny stellate and pyramidal cells in the barrels and septa of layer 4 rat somatosensory cortex. $J$. Physiol. (Lond.) 543, 49-70.

Celikel, T., Szostak, V., and Feldman, D. (2004). Modulation of spike timing by sensory deprivation during induction of cortical map plasticity. Nat. Neurosci. 7, 534-541.

Crochet, S., and Petersen, C. (2006). Correlating whisker behavior with membrane potential in barrel cortex of awake mice. Nat. Neurosci. 9, 608-610.

Dan, Y., and Poo, M. M. (2006). Spike timing-dependent plasticity: from synapse to perception. Physiol. Rev. 86, 1033-1048.

de Kock, C. P., Bruno, R., Spors, H., and Sakmann, B. (2007). Layer- and celltype-specific suprathreshold stimulus representation in rat primary somatosensory cortex. J. Physiol. (Lond.) 581, 139-154.

de Kock, C. P., and Sakmann, B. (2009). Spiking in primary somatosensory cortex during natural whisking in awake head-restrained rats is cell-type specific. Proc. Natl. Acad. Sci. U.S.A. 106, 16446-16450.

Frick, A., Feldmeyer, D., and Sakmann, B. (2007). Postnatal development of synaptic transmission in local networks of L5A pyramidal neurons in rat somatosensory cortex. J. Physiol. (Lond.) 585, 103-116.

Frick, A., Feldmeyer, D., Helmstaedter, M., and Sakmann, B. (2008). Monosynaptic connections between pairs of L5A pyramidal neurons in columns of juvenile rat somatosensory cortex. Cereb. Cortex 18, 397-406.

Frick, A., and Johnston, D. (2005). Plasticity of dendritic excitability. J. Neurobiol. 64, 100-115.

Frick, A., Magee, J., and Johnston, D. (2004). LTP is accompanied by an enhanced local excitability of pyramidal neuron dendrites. Nat. Neurosci. 7, 126-135.

Frick, A., Magee, J., Koester, H. J., Migliore, M., and Johnston, D. (2003). Normalization of Ca2+ signals by small oblique dendrites of CA1 pyramidal neurons. J. Neurosci. 23, 3243-3250.

Hamill, O. P., Huguenard, J. R., and Prince, D. A. (1991). Patch-clamp studies of voltage-gated currents in identified neurons of the rat cerebral cortex. Cereb. Cortex 1, 48-61.

Helmchen, F., Svoboda, K., Denk, W., and Tank, D. W. (1999). In vivo dendritic calcium dynamics in deep-layer cortical pyramidal neurons. Nat. Neurosci. 2, 989-996.

Hoffman, D. A., Magee, J. C., Colbert, C. M., and Johnston, D. (1997). K+ channel regulation of signal propagation in dendrites of hippocampal pyramidal neurons. Nature 387, 869-875.

Kampa, B. M., and Stuart, G. J. (2006). Calcium spikes in basal dendrites of layer 5 pyramidal neurons during action potential bursts. J. Neurosci. 26, 7424-7432.

Koester, H. J., Baur, D., Uhl, R., and Hell, S. W. (1999). Ca2+ fluorescence imaging with pico- and femtosecond two-photon excitation: signal and photodamage. Biophys. J. 77, 2226-2236.

Larkum, M. E. (1999). Calcium electrogenesis in distal apical dendrites of layer 5 pyramidal cells at a critical frequency of back-propagating action potentials. Proc. Natl. Acad. Sci. U.S.A 96, 14600-14604.

Larkum, M. E., and Zhu, J. J. (2002). Signaling of layer 1 and whisker-evoked $\mathrm{Ca} 2+$ and $\mathrm{Na}+$ action potentials in distal and terminal dendrites of rat neocortical pyramidal neurons in vitro and in vivo. J. Neurosci. 22, 6991-7005.

Larkum, M. E., Waters, J., Sakmann, B., and Helmchen, F. (2007). Dendritic spikes in apical dendrites of neocortical layer $2 / 3$ pyramidal neurons. $J$. Neurosci. 27, 8999-9008.

Larkum, M. E., Zhu, J. J., and Sakmann, B. (1999). A new cellular mechanism for coupling inputs arriving at different cortical layers. Nature 398, 338-341.

Lefort, S., Tomm, C., Floyd Sarria, J. C., and Petersen, C. (2009). The excitatory neuronal network of the $\mathrm{C} 2$ barre column in mouse primary somatosensory cortex. Neuron 61, 301-316.

Lisman, J. E. (1997). Bursts as a unit of neural information: making unreliable synapses reliable. Trends Neurosci. 20 38-43.

Magee, J. C., and Johnston, D. (1997). A synaptically controlled, associative signal for Hebbian plasticity in hippocampal neurons. Science 275, 209-213.

Mainen, Z. F., Joerges, J., Huguenard, J. R. and Sejnowski, T.J.(1995). A model of spike initiation in neocortical pyramidal neurons. Neuron 15, 1427-1439.

Manns, I. D., Sakmann, B., and Brecht, M. (2004). Sub- and suprathreshold receptive field properties of pyramidal neurones in layers $5 \mathrm{~A}$ and $5 \mathrm{~B}$ of rat somatosensorybarrel cortex. J. Physiol. (Lond.) 556, 601-622.

Markram, H., Lubke, J., Frotscher, M., and Sakmann, B. (1997). Regulation of synaptic efficacy by coincidence of postsynaptic APs and EPSPs. Science 275, 213-215.

Migliore, M., and Shepherd, G. M. (2002) Emerging rules for the distributions of active dendritic conductances. Nat. Rev. Neurosci. 3, 362-370.

Nevian, T., Larkum, M. E., Polsky, A., and Schiller, J. (2007). Properties of basal dendrites of layer 5 pyramidal neurons: a direct patch-clamp recording study. Nat. Neurosci. 10, 206-214.
Nowak, L. G., Sanchez-Vives, M. V., and McCormick, D. A. (1997). Influence of low and high frequency inputs on spike timing in visual cortical neurons. Cereb. Cortex 7, 487-501.

Panzeri, S., Petersen, R. S., Schultz, S. R., Lebedev, M., and Diamond, M. F. (2001). The role of spike timing in the coding of stimulus location in rat somatosensory cortex. Neuron 29, 769-777.

Petreanu, L., Mao, T., Sternson, S., and Svoboda, K. (2009). The subcellular organization of neocortical excitatory connections. Nature 457, 1142-1145.

Schaefer, A. T., Larkum, M. E., Sakmann, B., and Roth, A. (2003). Coincidence detection in pyramidal neurons is tuned by their dendritic branching pattern. J. Neurophysiol. 89, 3143-3154.

Schiller, J., Helmchen, F., and Sakmann, B. (1995). Spatial profile of dendritic calcium transients evoked by action potentials in rat neocortical pyramidal neurones. J. Physiol. (Lond.) 487( $\mathrm{Pt} 3$ ), $583-600$

Schubert, D., Kötter, R., Luhmann, H. J., and Staiger, J. F. (2006). Morphology, electrophysiology and functional input connectivity of pyramidal neurons characterizes a genuine layer va in the primary somatosensory cortex. Cereb. Cortex 16, 223-236.

Shadlen, M. N., and Newsome, W. T. (1995). Is there a signal in the noise? Curr. Opin. Neurobiol. 5, 248-250.

Sjöström, P. J., Rancz, E. A., Roth, A., and Häusser, M. (2008). Dendritic excitability and synaptic plasticity. Physiol. Rev. 88, 769-840.

Spruston, N., Schiller, Y., Stuart, G., and Sakmann, B. (1995). Activity-dependent action potential invasion and calcium influx into hippocampal CA1 dendrites. Science 268, 297-300.

Stevens, C. F., and Zador, A. M. (1998). Input synchrony and the irregular firing of cortical neurons. Nat. Neurosci. $1,210-217$.

Stuart, G. J., and Hausser, M. (2001). Dendritic coincidence detection of EPSPs and action potentials. Nat. Neurosci. 4, 63-71.

Stuart, G. J., and Sakmann, B. (1994). Active propagation of somatic action potentials into neocortical pyramidal cell dendrites. Nature 367, 69-72.

Stuart, G. J., Schiller, J., and Sakmann, B. (1997). Action potential initiation and propagation in rat neocortical pyramidal neurons. J. Physiol. (Lond.) 505(Pt 3), 617-632. 
Waters, J., Larkum, M. E., Sakmann, B., and Helmchen, F. (2003). Supralinear $\mathrm{Ca} 2+$ influx into dendritic tufts of layer $2 / 3$ neocortical pyramidal neurons in vitro and in vivo. J. Neurosci. 23, 8558-8567.

Waters, J., Schaefer, A., and Sakmann, B. (2005). Backpropagating action potentials in neurones: measurement, mechanisms and potential functions. Prog. Biophys. Mol. Biol. 87, 145-170.
Williams, S. R., and Stuart, G. J. (2000). Backpropagation of physiological spike trains in neocortical pyramidal neurons: implications for temporal coding in dendrites. J. Neurosci. 20, 8238-8246.

Zhu, J. J. (2000). Maturation of layer 5 neocortical pyramidal neurons: amplifying salient layer 1 and layer 4 inputs by $\mathrm{Ca} 2+$ action potentials in adult rat tuft dendrites. J. Physiol. (Lond.) 526(Pt 3), 571-587.
Conflict of Interest Statement: The authors declare that the research was conducted in the absence of any commercial or financial relationships that could be construed as a potential conflict of interest.

Received: 24 November 2009; paper pending published: 20 December 2009; accepted: 16 April 2010; published online: 18 May 2010.

Citation: Grewe BF, Bonnan A and Frick A (2010) Back-propagation of physiological action potential output in dendrites of slender-tufted L5A pyramidal neurons. Front. Cell. Neurosci. 4:13. doi: 10.3389/fncel.2010.00013

Copyright (c) 2010 Grewe, Bonnan and Frick. This is an open-access article subject to an exclusive license agreement between the authors and the Frontiers Research Foundation, which permits unrestricted use, distribution, and reproduction in any medium, provided the original authors and source are credited. 